\title{
Retraction Note to: Anti-Inflammatory Effects of Chronic Aspirin on Brain Arachidonic Acid Metabolites
}

\author{
Mireille Basselin $^{1} \cdot$ Epolia Ramadan $^{1} \cdot$ Mei Chen $^{1} \cdot$ Stanley I. Rapoport $^{1}$
}

Published online: 25 April 2015

(C) Springer Science+Business Media New York 2015

\section{Retraction Note to: Neurochem Res (2011)}

\section{6:139-145}

\section{DOI 10.1007/s11064-010-0282-4}

This article has been retracted on request of the Editor-inChief. The National Institutes of Health (NIH) has found that Dr. Mireille Basselin engaged in research misconduct by fabricating and/or falsifying data in "Basselin M, Ramadan E, Chen M, Rapoport SI, Anti-inflammatory effects of chronic aspirin on brain arachidonic acid metabolites. Neurochemical Research 36 (1) 139-145, 2011." Figure 2a-e was falsified. Please note none of the other authors are implicated in any way. Each of the co-authors of the manuscript has agreed to this retraction.

The online version of the original article can be found under doi:10. 1007/s11064-010-0282-4.

Epolia Ramadan

ramadanir@mail.nih.gov

1 Brain Physiology and Metabolism Section, National Institute on Aging, National Institutes of Health, Bldg. 9, Room 1S126, 9000 Rockville Pike, Bethesda, MD 20892, USA 